Vladimír Rudy; Juraj Kováč

\title{
VIRTUAL AND DIGITAL TRANSFORMATION AND GENERAL PRODUCTION ENVIRONMENTAL STRUCTURES
}

\author{
Vladimír Rudy \\ Technical University of Kosice, Faculty of Mechanical Engineering, Institute of Management, Industrial and Digital \\ Engineering, Park Komenskeho 9, 04200 Kosice, Slovakia, EU, vladimir.rudy@tuke.sk (corresponding author)

\section{Juraj Kováč}

Technical University of Kosice, Faculty of Mechanical Engineering, Institute of Management, Industrial and Digital Engineering, Park Komenskeho 9, 04200 Kosice, Slovakia, EU, juraj.kovac@ tuke.sk

Keywords: production system design, Industry 4.0, production environment, virtual design, production digitization Abstract: The future of intelligent manufacturing systems will be the era of Smart technologies coupled with complex automation, robotics and artificial intelligence. Already today, virtualization and the digital transformation of manufacturing systems, the pursuit of applying Industry 4.0 elements, and the industrial Internet platforms are becoming a presence. The advent of virtual and digital technology and breakthrough projection technologies to deliver a comprehensive, tailor-made manufacturing environment delivers a number of generally proclaimed benefits in terms of productivity, flexibility, production quality, including absolute responsiveness to meeting diverse and increasing customer demands for product performance. The benefits of designing production system structures as virtual models and then digitizing them are well known and, together with flexibility, meet the growing demands of customers. Any such qualitative change in the production environment entails a 'knowledge burden' on the designers of such production structures. They must be created on the basis of best practices, knowledge and knowledge that apply methods, procedures, tools, techniques and models of construction improvement and contraction, respectively. transformation (restructuring) of the production environment.

\section{Introduction}

Designing the structures of the manufacturing environment is a complex multi-level system, influenced by a large number of factors, both external and internal contradictions. Their overcoming is the basis of project activity methodologies, which are technically and technologically highly intellectually demanding and focused on realization of innovations, modernization or restructuring of production. The technological project of the production environment is the basic model of the structure of future production. In accordance with the competitiveness and technology of the product, it creates ideas of possible models of its future production. The development of design methodologies goes hand in hand with competition, market needs and product innovation. To build an investment and operationally profitable production system capable of quickly materializing changing, often unpredictable demands on the utility properties of products, responding to fluctuations in sales, etc. means to design modern technologies enabling spatial visualization of the future production environment, technological simulation of processes, their quality, performance characteristics of the system, including economic impacts on the company, etc. This path is only viable by improving the design methodology, integrating it into productive information and knowledge systems ensuring the desired quality and durability of the implemented projects. The science of designing the production environment (design theory, design philosophy) is characterized as a set of logical grouped knowledge and information about engineering design. Designing is therefore a complex area of theories, methods, procedures and techniques involving a broad field of engineering activities.

\section{Innovative methodologies for designing future production}

Designing today's complex and diverse manufacturing systems requires a comprehensive analysis of their operations in three spatial dimensions and over time. Only this approach is a guarantee of identification, optimization, resp. elimination of project shortcomings before their future physical implementation. Production group designers must be professional and specialist. They must have creativity and profound professional theoretical and practical knowledge of the issues they are dealing with in the project. In technical project solutions, it must have a sense of precision and addressing details as a limiting requirement for the success and implementation of a future project. It must manage to follow the development trends of designing new production structures and the direction of their development. Do not stay at the level of selection of outdated, time-consuming technical solutions, applied technologies and technical means. For designing production systems, adequate methodological procedures, 
VIRTUAL AND DIGITAL TRANSFORMATION AND GENERAL PRODUCTION ENVIRONMENTAL STRUCTURES

Vladimír Rudy; Juraj Kováč

algorithms and tools have been developed in the long term, which will ensure higher efficiency of solutions in individual stages of the project process. The creative nature of project activities creates pressure for interactive generation of solution variants, their evaluation, optimal selection and detailed elaboration. If the aim is a highquality level of project solution, it is necessary to consider high variation. This results from the real nature of engineering production processes, typology, structural layout, localization of production systems in space, time, their economic efficiency and so on. The methodological design procedures used in each stage of the solution must be closely linked.

Stages of the solution are most often presented by models in which the project activity is decomposed into hierarchical levels. The philosophy of innovative, interactive design is based on the assumption that solving project problems takes place in three basic phases [1]:

- A set of variants of project task solutions is being created in accordance with the set objectives. Various methods (analytical, morphological, hierarchical generation, etc.) can be used to determine variants of reference solutions. It is necessary to create more options and to define permissible solutions in the next stage. For less complex tasks, it is possible to use intuitive ways of generating variants based on reference type patterns. - Allowable solutions are defined. In this phase, it is necessary to exclude inappropriate variants of the solution either on the basis of intuitive approaches, resp. based on the use of logical and mathematical methods. It is advantageous to evaluate variants using methods which are based on functional and parametric admissibility. In the first case, it is possible to evaluate in particular the functional links of the overall solution structure (graphs, bond models, mathematical-logical models, etc.). In the latter case, it is necessary to specify a set of critical, i. solution parameters.

- The optimal solution of project tasks is selected as the final stage. The optimal variant can be obtained on the basis of comparative methods (reference projects), on the basis of simulation activities and the like. The design methodologies are based on the creation of 3D models of production technology and their transformation into virtual scenes enabling digitization and subsequent simulation of their arbitrary production characteristics (e.g. feasibility of operations on production technology, verification of calculated production times of production, etc.). The primary base for 3D creeping, respectively. virtual workplaces can be used simple variant designs processed in 2D modifications of the spatial structure of the production environment. The general methodological sequence of the production structure project assuring its realization and operational success is illustrated in fig. 1 .

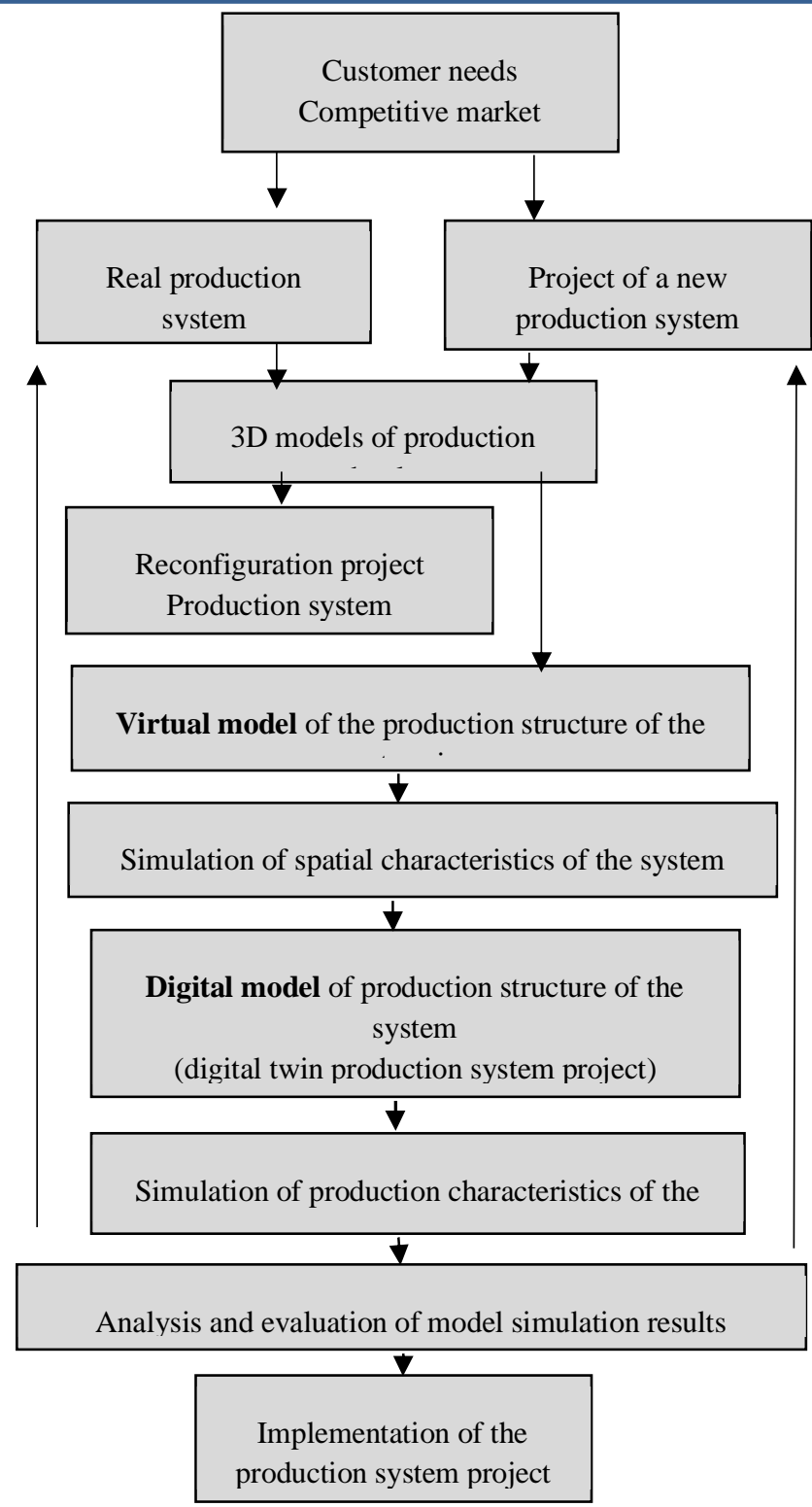

Figure 1 Illustration of the design methodology of the new production structure

The most important benefit of virtual design is shortening the innovation cycle of the production system during its reconfiguration, resp. overall development cycle in designing a new production structure. The functionality of the design as a whole and its components is checked after each operation performed throughout the model. Tests and simulations thus help to detect errors and deficiencies that would come to light only when the final production project was implemented and would require backward, time-consuming and economically demanding changes. This is a significant contribution of high technology compared to classical technical preparation of production. As the product innovation cycle is greatly shortened, products can be upgraded more often or faster 
Vladimír Rudy; Juraj Kováč

to respond to changing market demands and thus increase competitiveness. The condition is the integration of virtual technologies with other CAx technologies, which are used in the operation of the production structure and are known as PDM systems. In particular, the advances in hardware, software and information technology and imaging technology have made possible innovative changes. Advanced reprographics and presentation technology integrated with interactive software systems enables today a new way of working for production system designers. Virtual models of production projects are designed in sequence:

1) processing of $3 \mathrm{D}$ models of production technology incorporated into the project,

2) processing of the models of the production hall in which the project will be situated, including its operational infrastructure (heating, air-conditioning, exhaust, distribution of technical media, etc.),

3 ) creation of $3 \mathrm{D}$ production structure of future production,

4) transforming the model into a virtual reality (e.g. converting a 3D model to VRML). 3D modelling techniques only allow the creation of a visual illusion of the "artificial" production space from the perspective of the observer. The virtual models are used to simulate the spatial characteristics of the future system (expediency, optimal layout of production technology, spatial characteristics of the size of warehouses and auxiliary areas, aisle size, transporthandling characteristics, ergonomics of production equipment operators and manipulation with production objects, measurements, etc.) . Virtual models of existing real productions that were not previously treated as 3D projects, e.g. in case of need of technological reconfiguration of production system (change of production technique, change of spatial configuration of production premises etc.) they are modelled in sequence:

1) spatial digitization (scanning) of the production structure (production space, production technology, e.g. 3D scanners SCAN in and BOX Structured Light),

2) concept of spatial structure of the system,

3) transforming data into a virtual environment.

Model visualization techniques and imaging methods currently provide multiple options for transforming physical models of manufacturing system projects into 3D rendered scenes. Today's market has a wide range of SW and HW resources. The development of these devices follows advances in virtual technology development and has a very dynamic character:

- technical equipment for high-volume scanning (production halls, production technology), - 3D camera systems (stationary, mobile, drones),
- software technologies for visualizing workflows in virtual reality (Twinmotion, Taracos, Plavis, Factory Design Suite, Vuforio studio). Twinmotion is a program that works on the principle of real-time visualization. - technical means for training, sensory perception and education in virtual reality (eg Oculus Touch Controller), - HW tools for virtual object handling (Oculus Rift virtual helmets, Samsung Gear VR, nReal Light glasses, Olympus EyeTrek Insight EI-10 ...).

"Headset" is a set of technical means for training, perception and working in the virtual world. It consists of an Oculus Rift virtual helmet with an OLED 1080x1200 pixel resolution display with a $90 \mathrm{~Hz}$ refresh rate and integrated headphones, right and left position sensors, and two Oculus Touch hand-held motion control units. They are used in the Oculus Home SW application and have a wide spectrum of applications from games to research activities. An illustration of the design work is shown in fig. 2.

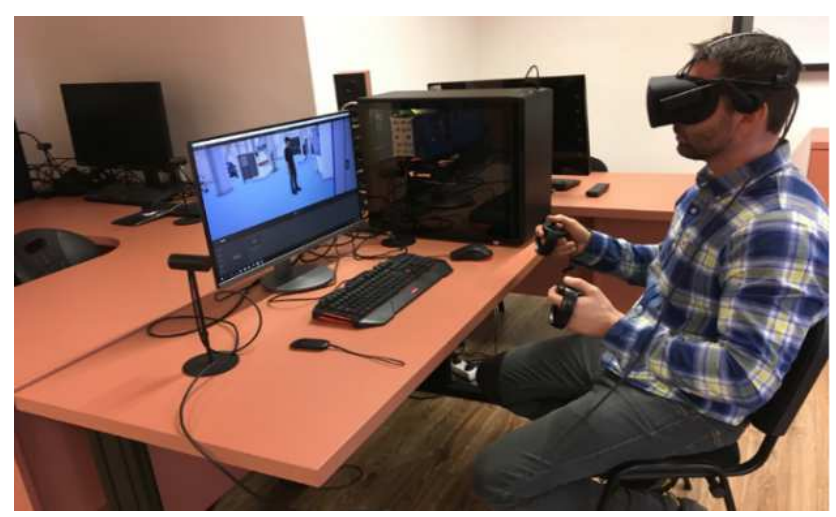

Figure.2 Verifying the deployment of production technology in the virtual scene

The designer 3D model of the production structure project) can be realized from the basis of 2D layout solutions, which can be partially spatially optimized or manipulated with the models of production technology directly in the 3D environment, respectively. create their virtual modifications directly in the virtual reality. An illustration of designing a virtual project of manufacturing structure by means of gloves (DataGloveII) is shown in fig. 3. When interactively designing production systems in virtual reality, it is recommended to follow the principles specified in the stated design methodologies. The manner of arrangement of the means of production can be varied (longitudinal, transverse, oblique, irregular). 
Vladimír Rudy; Juraj Kováč

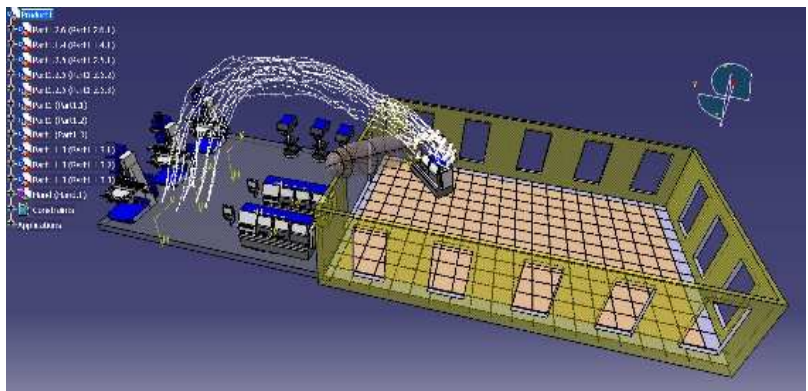

Figure 3 Manipulating 3D models in the virtual scene with the Data Glove II

An example of an innovative approach to solving the deployment tasks of production technology during construction, resp. The drone is equipped with a mini projector, which gradually reflects a specially created QR code (VuMark) created in the Vuforia studio SW environment on the real floor of the production hall. Designer through a virtual helmet Oculus Rift, respectively. monitors the positioning of the machine model using a smartphone or tablet camera. the projector only shows a plan view of the device visible to the naked eye. After marking the machine position, resp. placing the drone on the marked position moves the drone to the next position in terms of the project. The precondition for the precision of the deployment of the production technique is the processing of the model of the production structure at a scale of 1:1. This ensures that the model shown in mixed reality is dimensionally matched to the physical production equipment to be located in the production space fig. 4 .

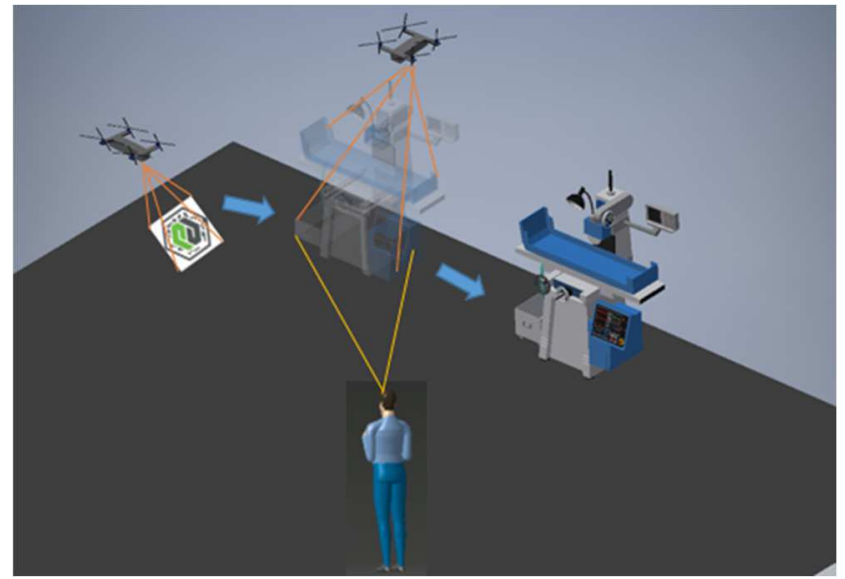

Figure 4 Creation of real production structure by drone

\section{Production systems of the future}

The production systems of the future are designed as new generation systems in which production is based on knowledge. The most advanced software, information and communication technologies are applied in the projects. They are organized in new decentralized and adaptable production structures. The vision of future production development is focused mainly on the development of new products and services with high added value, new production technologies, new production systems, organization and management systems, etc., supported by the infrastructure of education, research and development. A high-quality technological project is the first basis for the implementation stages and depends on it the future level of production in the new, respectively. reconfigured system. It represents a future picture of the nature and conditions of production. Therefore, it is necessary to carry all the features of the model. Only then will it be at least distant from the optimal solution in functions, structure, parameters, etc. Working out good new production projects means finding an optimal, team-based compromise of views on a range of strategic issues that need to be answered before a technical solution is reached. It is necessary to have sufficient complex and reliable documents both in conceptual and detailed phases of the solution of the respective project. In particular, innovators working on changes in production need to focus their processes on the use of the latest and most advanced technical knowledge. Information and knowledge should be used in both experimental and practical activities. In doing so, a complex set of technical, economic, social and environmental factors must be considered. These productions must be constructed as systems in which production is friendly to the "comfort of life on earth" fig. 5.

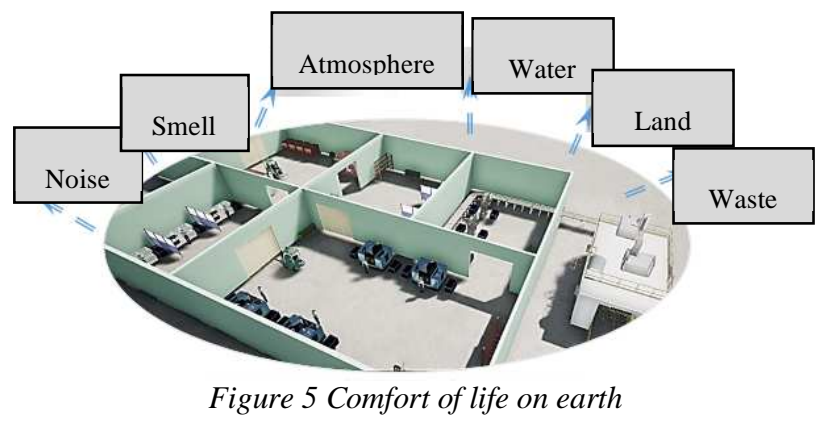

The ecological dimension of their operation must be part of pre-implementation analyses and project simulations. In critical cases, it must be superior to the operational (technical, technological and economic) feasibility criteria of the production system. Simulation analyses must guarantee that the production of such production will be "clean" and economical. Environmentally friendly and man-made production, maximally recyclable, energyefficient, silent, operating on "considerate technologies" (odor, noise, dust, vibration ...). They will be modified as complex philanthropic complexes with a specific corporate culture. They will be managed on a communication and information platform with a responsible and considerate approach to employees to generate knowledge for their own development. The design activity will have to become even more flexible so that it can adapt to market pressure 
VIRTUAL AND DIGITAL TRANSFORMATION AND GENERAL PRODUCTION ENVIRONMENTAL STRUCTURES

Vladimír Rudy; Juraj Kováč

within the time and economic limits of interest to the customer. That is why it is necessary to have enough comprehensive and reliable documents, both in conceptual and detailed phases of the solution of the respective project. Looking at the future, it is clear that projection organizations are facing substantial changes in overall management, resources used and project resources. The research and development of means of production is increasingly international. The design activity of modern production structures will be an increasingly demanding problem. It will have to become more flexible in order to adapt to trade pressure, diverse production cultures, together with partner integration and the like. Standardization and standardization problems will come to the forefront, for which adequate resources in system theories will have to be sought. The amount of information that needs to be gathered, collected, transmitted, stored and searched will increase dramatically. Decentralization and specialization will continue to increase. While the software of solo PC technology is sufficient for project creation now, projects in project systems will be realized in the future only on the basis of computer networks. Increased emphasis on customer satisfaction and the need to create the lowest cost possible will be the driving force. As a result of the licensing and diversification of projects, a greater number of projects will need to be addressed simultaneously. Efforts will be made to bring projects as far as possible into the phase of deciding whether or not to continue them. This will require a lot of information from project management and will need to learn to organize them quickly when deciding on partial goals. The characteristics limiting the solutions of future projects, conceptually modelled on the principles of the plants of the future are illustrated in fig. 6 .

\section{Conclusions}

The external components of the corporate culture will be promoted to the level of immediate, informal cooperation with suppliers. Supply companies will be organized in global production networks, coordinated on the principles of high flexibility and reliability of supply. The customer will become a partner of the company and the production "on-line coordinator" of his order in the whole value chain of his production. These facts will also greatly affect the project concepts of the arrangement and structure of the administrative premises of such products, etc. Future companies should have fewer goals and more enjoyment of their daily work. There will be fewer controls on goals and more enthusiasm for new ideas and results.

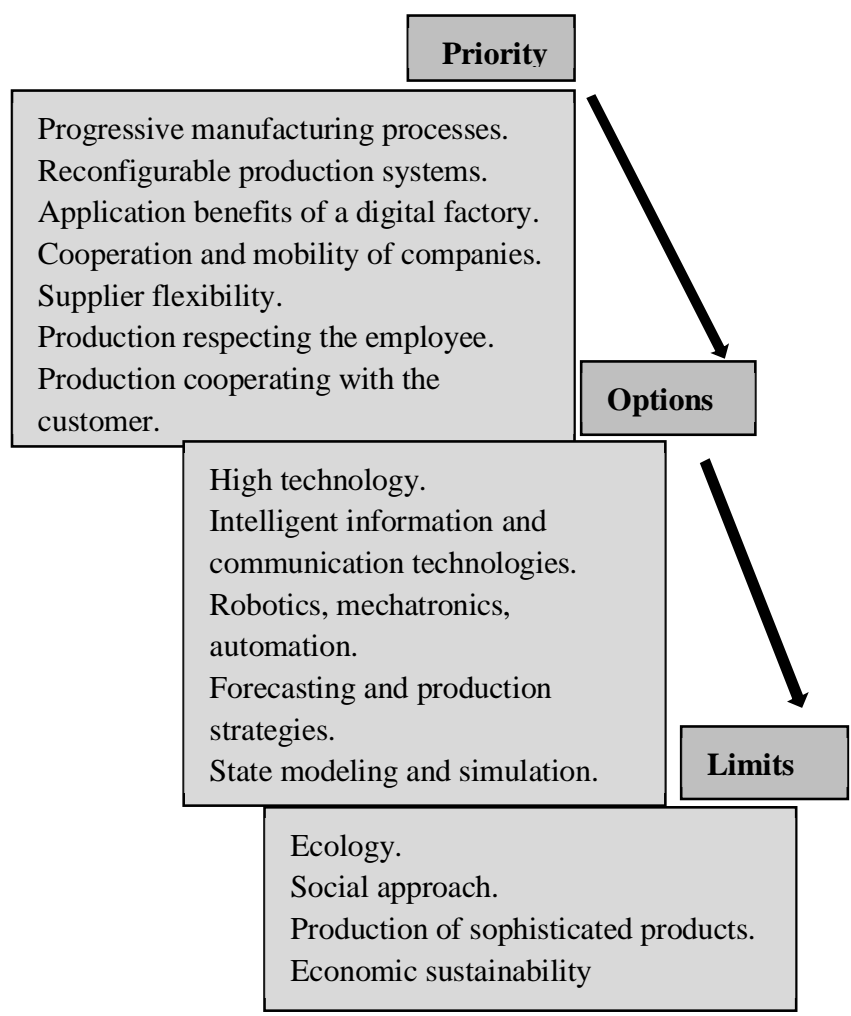

Figure. 6 Limits of the future production concept.

\section{Acknowledgement}

This article was created by implementation of the grant project APVV-17-0258 "Digital engineering elements application in innovation and optimization of production flows", VEGA 1/0438/20 "Interaction of digital technologies to support software and hardware communication of the advanced production system platform" and KEGA 001TUKE-4/2020 "Modernizing Industrial Engineering education to Develop Existing Training Program Skills in a Specialized Laboratory."

\section{References}

[1] KOVÁČ, J., RUDY, V., KOVÁČ, J.: Metodika projektovania výrobných procesov 2, inovačné projektovanie výrobných systémov, Košice, Technická univerzita v Košiciach, 2018. (Original in Slovak)

[2] GREGOR, M., MIČIETA, B., KRAJČOVIČ, M. et al.: Súbor prednášok 50. rokov, Katedra priemyselného inžinierstva, Žilinská univerzita v Žiline. (Original in Slovak)

[3] GREGOR, M., MEDVECKÝ, Š., MIČIETA, B., MATUSZEK, J., HRČEKOVÁ, A.: Digitálny podnik, Ústav konkurencieschopnosti a inovácií, 2006. (Original in Slovak)

[4] BUBENÍK, P., BUBENÍKOVÁ, E., KORBEL, P., NAGY, P.: Informačné technológie pre podnikovú prax, Edis,ŽU v Žiline, 2004. (Original in Slovak) 
[5] POÓR, P., ŠIMON, M., \& KARKOVÁ, M.: CMMS as an effective solution for company maintenance costs reduction, Production Management And Engineering Sciences, 2015.

[6] GREGOR, M., HODON, R., BIŇASOVÁ, V., DULINA, L., GAŠO, M.: Design of SimulationEmulation Logistics System, 4th EAI International Conference on Management of Manufacturing Systems, MM Science Journal, 2018.

[7] FURMANN, R., FURMANNOVÁ, B.: Logistics and digital twin, InvEnt 2017: Industrial Engineering Invention for Enterprise, Wydawnictwo Fundacji Centrum Nowych Technologii, Szczyrk, PL, 2017.

[8] GRZNAR, P., GREGOR, M., MOZOL, S., KRAJCOVIC, M., DULINA, L., GASO, M., MAJOR, M.: A System to Determine the Optimal Work-inProgress Inventory Stored in Interoperation Manufacturing Buffers, Sustainability, Vol. 11, No. 14, pp. 1-36, 2019. doi:10.3390/su11143949

[9] DULINA, L., EDL, M.,FUSKO, M.,RAKYTA, M., SULIROVA, I.: Digitization in the Technical Service Management System, 4th EAI International Conference on Management of Manufacturing Systems, MM Science Journal. No. 1 (2018). p. 2260 - 2266. ISSN 1803-1269.

[10] FUSKO, M., RAKYTA, M., KRAJCOVIC, M., DULINA, L., GASO, M., GRZNAR, P.: Basics of
Designing Maintenance Processes in Industry 4.0., 4th EAI International Conference on Management of Manufacturing Systems, MM Science Journal, 2018.

[11] STRAKA, M., LENORT, R., KHOURI, S., FELIKS, J.: Design of large-scale logistics systems using computer simulation hierarchic structure, International Journal of Simulation Modelling, Vol. 17, No. 1, pp. 105-118, 2018.

[12] BINASOVA, V., BUBENIK, P., DULINA, L., DURICA, L., EDL, M., KRAJCOVIC, M., MICIETA, B.: Delegate MASs for Coordination and Control of One-Directional AGV systems: a Proofof-Concept, The International Journal of Advanced Manufacturing Technology, Vol. 94., No. 1-4, pp. 415-431, 2018.

[13] WICHER, P., STAŠ, D., KARKULA, M., LENORT, R., BESTA, P.: A computer simulationbased analysis of supply chains resilience in industrial environment, Metalurgija, Vol. 54, No. 4, pp. 703706, 2015.

[14] EDL, M., LERHER, T., ROSI, B.: Energy efficiency model for the mini-load automated storage and retrieval systems, International Journal of Advanced Manufacturing Technology, Vol. 2013, pp. 1-19, 2013. 